\title{
ESTUDO DE OPERAÇÕES CITY LOGISTICS PARA AUMENTO DA COMPETITIVIDADE EM UMA EMPRESA DE APARELHOS AUDITIVOS NA CIDADE DE CAMPINAS-SP
}

\author{
D. C. Monteiro ${ }^{1 *}$; F. Y. Shibao ${ }^{1}$, N. F. Souza ${ }^{1}$ \\ 1 Centro de Pós-graduação Universidade Nove de Julho, 05001-100, Água Branca, São Paulo, SP, Brasil \\ *davidcmonteiro@ hotmail.com
}

\section{RESUMO}

Discute-se no presente artigo as possibilidades de operação logística viabilizada a partir das necessidades e das ideias patrocinadas por uma empresa que comercializa aparelhos auditivos na cidade de Campinas, no interior paulista, que para enfrentar os sérios problemas logísticos de distribuição de aparelhos auditivos nessa cidade, precisou inovar no campo da distribuição de seus produtos. Contextualiza-se que a logística muitas vezes é algo intuitivo, o que, na prática, costuma levar o gestor justamente ao estudo da temática, merecedora sempre de ratificação e permanente estudo. Objetivou-se rever questões centrais
\end{abstract}

da logística, especificamente objetivando-se expor como a disciplina de fato auxiliou determinada organização a resolver problema concreto de distribuição de seus produtos. O percurso metodológico passa por revisão de literatura e estudo de caso, justificando-se a pesquisa pelo seu elevado valor prático. Os resultados obtidos apontam a validade da solução adotada por determinada empresa, esta constante de dirigir-se até onde o cliente estava por intermédio de vendedores especializados, apresentando a medida a recuperação e um aumento significativo da clientela da companhia estudada.

PALAVRAS-CHAVE: Logística; City Logistics; Aparelho de Amplificação Sonora Individual; Vantagem Competitiva; Campinas.

\section{STUDY OF CITY LOGISTICS OPERATIONS FOR INCREASED COMPETITIVENESS IN A HEARING APPARATUS IN THE CITY OF CAMPINAS-SP}

\begin{abstract}
Discuss this article logistics operation possibilities made possible from the needs and ideas sponsored by a company that sells hearing aids in a large city paulista inside: Campinas. It turns out that, to address the serious logistical problems of distribution of hearing aids in this city, the organization needed to innovate in the field of distribution of its products. Contextualizes that logistics is often intuitive, which, in practice, usually leads the manager to the study of the subject, always deserving of ratification and permanent study. The objective was to review central logistics issues,
\end{abstract}

specifically aiming to expose how the discipline actually helped a particular organization to solve the concrete problem of distribution of its products. The methodological course is reviewed by literature and case study, justifying the research for its high practical value. The results obtained indicate the validity of the solution adopted by a certain company, this constant to go as far as the customer was through specialized vendors, presenting the measure the recovery and a significant increase in the clientele of the company studied.

KEYWORDS: Logistics; City Logistics; Hearing AIDS; Competitive Advantage; Campinas. 


\section{INTRODUÇÃO}

O envelhecimento da população mundial exige estudos, soluções e pesquisas específicas ligadas aos idosos, já que este grupo apresenta características peculiares de saúde física e mental. Dentre as alterações mais comumente encontradas destacam-se os prejuízos sensoriais como acontece com a deficiência auditiva que pode levar ao isolamento social, à depressão e até mesmo ao abandono das atividades diárias, o que é sem dúvida algo que não se deseja (GATES et al., 2003).

Em virtude da relação muito próxima entre a perda auditiva e o avanço da idade de cada pessoa, pressupõe-se que com o aumento da população brasileira mais velha, também ocorra o aumento de pessoas com deficiência auditiva, principalmente se ações de saúde coletiva direcionadas aos adultos, jovens e integrantes das faixas mais avançadas de idade não se concentrarem em medidas para a real promoção da saúde auditiva e a prevenção dessa deficiência, sabendo-se que a prevenção, neste campo, é essencial (CRUZ et al., 2013).

Em um estudo qualitativo realizado em saúde auditiva localizada na cidade de Itajá no Estado de Santa Catarina, contando com 19 idosos usuários de aparelhos de amplificação sonora individual (AASI), os pesquisadores concluíram que integrantes da terceira idade deficientes auditivos atribuíram a possibilidade de acesso ao AASI, justamente à implantação do Serviço de Atenção à Saúde Auditiva próximo às regiões de suas moradias, visto que esse tipo de serviço tende a organizar a oferta e a disponibilidade dos atendimentos (FIALHO et al., 2009). Portanto, a disponibilidade dos serviços aliada à proximidade geográfica passa a ser um facilitador para o acesso à reabilitação auditiva.

Em uma pesquisa realizada nas cidades de Montes Claros (MG), Santa Maria (RS), Belo Horizonte (MG) e Canoas (RS), revelou que um usuário aguarda de três a seis meses para iniciar o processo de adaptação do aparelho auditivo. Os resultados deste estudo mostraram possibilidades iniciais para a construção de estratégias e ações operacionais de logística que possam melhor atender ao usuário, sobretudo com maior atenção aos idosos acima de 60 anos (JARDIM; MACIEL; LEMOS, 2016).

Em outra pesquisa realizada na Finlândia, constatou-se que apenas 30\% da população mais envelhecida com deficiência auditiva possuíam AASI e somente 55\% desses faziam o uso do dispositivo em tempo integral. As razões para a não utilização foram a não percepção de melhora na audição, quebra do aparelho e a dificuldade de manuseio do equipamento em função do tamanho reduzido das próteses auditivas, especialmente se considerando a presença frequente de alterações fisiológicas importantes em alguns idosos (LUPSAKKO; KAUTIAINEN; SULKAVA, 2005).

Verificou-se que o Brasil ainda é carente de estudos que relacionem a prevalência da deficiência auditiva com a presença de serviços de saúde. Obter informações sobre o uso dos serviços pelos idosos com deficiência auditiva pode auxiliar na melhor formulação de políticas públicas que visem à prevenção da saúde auditiva e a potencializar as ações dos serviços já existentes. O livre comércio na sociedade atual provoca mudanças constantes de arquétipos no cenário de aparelhos auditivos e por consequência traz o estímulo de novas ideias para a solução de problemas, sejam problemas somente comerciais, sejam aqueles que envolvam outras questões, como a importância da logística (CARVALHO, 2016).

A própria oferta de bens mais diversificados, seja pela necessidade dos públicos-alvo ou pela inovação promovida pelas diversas indústrias, fazem com que novos e velhos problemas mobilizem pessoas na direção de um atendimento comercial específico, ocorrendo a dinamização na oferta de diversas soluções. Principalmente, porque os dados são preocupantes, tendo em vista os 
possíveis benefícios que o uso do aparelho de amplificação sonora individual (AASI) pode oferecer, tais como a melhoria nas situações de comunicação e contribuição para a preservação da capacidade funcional e das habilidades cognitivas dos indivíduos com idade avançada (GATEHOUSE; NAYLOR; ELBERLING, 2006).

A cidade de Campinas situa-se a cerca de $100 \mathrm{~km}$ da capital do Estado de São Paulo, ocupando uma área de $795,7 \mathrm{~km}^{2}$, com uma população de 1.200 .000 habitantes a distribuir-se por 312 bairros (IBGE, 2016). Apesar da grande malha viária e de bons aspectos intermodais de transporte, as distâncias entre as populações mais periféricas e os principais centros comerciais é grande, demandando intensa preocupação quanto ao acesso entre produtores, prestadores de serviços e consumidores diversos. O público periférico, deste modo, sem querer acaba por contribuir com as novas dinâmicas logísticas (MARTINS, 2015).

Neste sentido, a empresa objeto desse estudo que comercializa e presta serviço para deficientes auditivos notou ligeira perda de clientes com o passar do tempo; para tanto foi realizada uma pesquisa no ano de 2014 no qual foi identificado que $72 \%$ de seu público reside na região periférica da cidade, ou seja, em bairros residenciais distantes do centro comercial, em média algo entorno de $20 \mathrm{~km}$. Assim, ratifica-se, a distância entre a residência dos clientes e a loja de vendas dos aparelhos auditivos foi a causa central da perda dos clientes sob estudo de caso. Desta maneira, surgiu a seguinte questão da presente pesquisa: facilitando-se o acesso do deficiente auditivo ao uso e à manutenção do aparelho da amplificação sonora individual aumentará a busca por esses serviços especializados?

Objetivou-se rever questões centrais da logística, especificamente objetivando-se expor como a disciplina de fato auxiliou determinada organização a resolver problema concreto de distribuição de seus produtos. Os procedimentos metodológicos passaram pela revisão de literatura, estudo de caso, justificando-se a análise pelo seu grande valor prático. Além desta introdução, no próximo tópico será apresentada a fundamentação teórica sobre logística, venda "porta a porta", a questão da City Logistics e a descrição da cidade de Campinas; posteriormente os materiais e métodos e a seguir os resultados seguidos de discussões e finalmente as considerações finais.

\section{FUNDAMENTAÇÃO TEÓRICA}

Neste tópico será apresentado a logística e venda "porta a porta", City Logistics e a descrição da cidade de Campinas.

\subsection{LOGÍSTICA E VENDA "PORTA A PORTA"}

A entrega ou o atendimento urbano por vezes é vista de modo negativo, por isso se faz necessárias mudanças de conceitos e modelos para a melhoria da vida nos centros urbanos, assim como propor solução de novos problemas, trazendo rentabilidade com um viés sustentável, uma vez que o transporte urbano de mercadorias é uma peça fundamental para o desenvolvimento de qualquer cidade (OLIVEIRA et al., 2016).

Com o advento da globalização e o aumento da concorrência, como lembrou Razzolini (2013), as empresas passaram a necessitar que seus produtos estivessem sempre disponíveis quando os clientes por eles busquem, pois já se sabe que quando um produto não está disponível ao cliente, este opta por comprar o bem em outro local ou procurar a prestação daquele serviço na concorrência, justamente para não ficar sem ele. 
A logística de armazenagem, nesse contexto, costuma iniciar os processos e oferecer ferramental logístico necessário, implicando em considerar a garantia de que os produtos estejam prontos para as entregas imediatas requeridas, ou que sejam urgentemente repostas a fim de quando for o caso regular o respectivo estoque.

Assim, trata-se de ação de gestão voltada para manter o que é necessário para suprir o que a clientela deseja, seja ela externa ou interna de uma organização (CHRISTOPHER, 2010). Outro tema que certamente mais integra o assunto da logística é o da logística de distribuição, também denominada outbound, trata da saída dos produtos manufaturados, podendo ser o produto final ou o produto semiacabado.

Em conformidade com o que pensavam Bowersox et al. (2011, p. 56), tem-se que a logística de distribuição "basicamente liga a empresa a seus clientes, pois é através desta que é realizado o processamento de pedidos e as entregas dos produtos nos pontos de consumo".

Ainda nessa linha de pensamento, Novaes (2007) afirmou que o objetivo geral da distribuição física, é levar os produtos certos para os lugares certos, no momento certo e com o nível de serviço desejado, sempre pelo menor custo possível. Esta área correlaciona-se diretamente com o departamento de marketing da empresa, mais especificamente da logística, que antes se conhecia somente como setor de transportes e entrega.

O conceito que contempla o relato acima pode ser chamado de "Door to Door" ou "venda porta a porta" que para Kotler (1999) reforçou uma economia baseada em um padrão de consumo cada vez mais horizontalizado.

Venda porta a porta consiste, como esclareceram Miyata e Suzuki (2013), em efetuar visitas aos possíveis compradores objetivando a oferta de determinados produtos ou serviços. Tal sistemática de vendas historicamente conecta-se a alguns produtos em especial como perfumes, consórcios, produtos de limpeza para o lar e produtos tecnológicos. Para o desenvolvimento desta atividade, sugere-se que o planejamento diário dos vendedores seja bem formulado, haja vista ter que percorrer de casa em casa e ruas e mais ruas.

Miyata e Suzuki (2013) mostraram ainda que empresas como Avon e Natura, são precursoras no que tange venda porta a porta. Seus resultados fomentaram a inauguração de novos centros de distribuição nos últimos anos, dentro de seus planos de reestruturação, focando na redução dos custos de distribuição, visando diminuir o tempo de entrega de produtos, e mais qualidade no atendimento e satisfação da clientela.

O sistema porta a porta teve seu auge nas décadas de 1950 a 1970 nos Estados Unidos, sendo até hoje muito utilizada pelo mundo - embora em declínio, principalmente pelo fator segurança. Assim, grandes cidades como New York e São Paulo costumam criar obstáculos para receber vendedores neste sistema, enquanto cidades pequenas do interior do Brasil, por exemplo, até hoje aceitem bem este tipo de venda (CHRISTOPHER, 2010).

Um dos caminhos para bem resolver estes problemas é a questão da City Logistics, a seguir examinada.

\subsection{A QUESTÃo DA CITY LoGISTICS}

City Logistics ou logística das cidades é temática que tem como objetivo aumentar a eficiência e reduzir os efeitos negativos dos processos e atividades comerciais ao enfrentar os problemas das cidades urbanas, ao mesmo tempo em que é área do conhecimento a apoiar o desenvolvimento sustentável dos espaços urbanos (FIGUEIREDO; LAMOUNIER, 1997). 
Grandes projetos de investigação têm sido realizados a partir do final do século passado, indicando que o estado da logística das áreas urbanas por quase todo o planeta é bastante crítico. A situação exige uma análise exaustiva e participação ativa das autoridades e empresas a fim de resolver os problemas crescentes relativos ao transporte coletivo, mobilidade urbana e saúde da pessoa idosa e definir as soluções sustentáveis que promovam o desenvolvimento econômico e melhora das condições de vida nas cidades, passando, aqui, pela questão da distribuição mais inteligente e efetiva de bens e serviços. E a fim de promover atividades de logística inovadoras e eficientes, a City Logistics tem lançado muitas iniciativas, especialmente em termos de redução do impacto ambiental e qualidade de serviço na alocação de materiais diversos, reciclagem de materiais, transporte de vários bens, acessos múltiplos etc. (FIGUEIREDO; LAMOUNIER, 1997).

No entanto, as mudanças são lentas e as necessidades de caráter ambiental, as distâncias entre os pontos comerciais, as distâncias entre as pessoas, o número de veículos e a quantidade do que precisa ser deslocado para atender a todos acaba por estabelecer novos desafios. O principal problema é a falta de atividades de planejamento e política global de longo prazo que de fato se debruce sobre a logística da cidade. As decisões dos administradores das cidades são muitas vezes inadequadas, sem a real análise da situação existente e interação de caráter logístico das áreas metropolitanas e seus arredores, faltam pesquisa e estudos multidisciplinares sobre o que vem a ser a cidade logística (TADEU, 2011).

Uma estratégia de logística urbana deve ser vista com um plano de longo prazo para melhorar a qualidade de vida dos moradores, sendo que suas decisões e ações devem ser coordenadas de forma interna e externa para o fluxo eficiente de produtos, informações. bens e para as pessoas (WITKOWSKIA; KIBA-JANIAK, 2014).

Com o crescimento da população urbana, o volume de bens e os fluxos de tráfego também estão crescendo. A expansão e o desenvolvimento econômico das cidades são as principais forças motrizes. Os municípios dependem da eficiência de sistemas logísticos para se tornarem ou permanecerem viáveis, portanto, seu maior desenvolvimento e progresso econômico estão intimamente ligados a uma maior expansão das atividades de logística, principalmente a que diz respeito ao transporte (TADEU, 2011).

Assim, tem se mostrado um grande desafio reduzir significativamente o transporte rodoviário de mercadorias, por exemplo, sem afetar fortemente (ao menos sem planejamento) as necessidades da cidade e seus habitantes. A fim de compreender as dimensões de logística da cidade, é desejável conhecer as características da logística, dos transportes e dos fluxos comerciais, bem como dos sistemas que permitem a sua execução. $\mathrm{O}$ volume dos fluxos está diretamente relacionado com o tamanho da cidade. No entanto, além de bens de consumo, é necessário examinar os fluxos de bens intermediários, matérias-primas, materiais de construção e outros aspectos. Por outro lado, o volume dos fluxos depende em grande medida das características geográficas e espaciais, da organização espacial das funções urbanas, da infraestrutura de logística e o papel da área observada na boa composição do fluxo de produtos a um nível superior (PANHAM; MENDES; BREDA, 2016).

Portanto, os volumes de fluxo de serviços e principalmente de bens nas cidades que são os nós logísticos importantes e significativamente mais elevados, estes como resultado direto dos fluxos de trânsito e da falta de planejamento urbano, implicam no crescente papel dos sistemas de logística na reconfiguração dos fluxos globais, regionais e nacionais. Esses fluxos incluem todos os movimentos de mercadorias gerados pelas necessidades das entidades econômicas, todas as entregas e recolha dos produtos básicos, materiais, materiais auxiliares e de consumo, afora os seus resíduos; dizem respeito também às entregas ao domicílio resultantes da venda por intermédio do $e$ commerce (LEONG et al.,2016). 
O setor de logística foi influenciado por uma série de tendências globais e a organização e execução de atividades de logística na cidade depende de uma série de fatores que descrevem o complexo sistema social e econômico da cidade e seu ambiente. Esses fatores são de categorias variáveis e sua análise pode identificar os problemas e a direção para o futuro desenvolvimento da logística da cidade. Embora seja, no Brasil, o sistema de transporte rodoviário de mercadorias pouco monitorado, este tem um forte componente urbano, carecendo, pois, de maior atenção e investimentos (FERRI; CHAVES; RIBEIRO, 2015).

Além disso, os veículos comerciais com peso bruto superior a 3,5 toneladas que estão sendo utilizados para a distribuição de mercadorias nas zonas urbanas, representam $10 \%$ do número total de veículos na rede de ruas das cidades europeias, e a sua participação nos fluxos de tráfego urbano (veículos/quilômetro) está compreendido entre 10 a 20\%. Dado que pequenos veículos de distribuição (vans e veículos do tipo pick-up) e os automóveis de passageiros estão cada vez mais sendo utilizados para a distribuição de bens, tal participação rodoviária do transporte de mercadorias é significativamente maior, ocasionando maior tráfego em tais cidades (PANHAM; MENDES; BREDA, 2016). Toda essa situação fez gerar uma série consequências e mudanças que, baseadas na logística, foi fazendo mudar a realidade.

Desde os anos 1980, a parcela destes custos diminuiu de $13,1 \%$ para $7,1 \%$, enquanto a percentagem dos custos de transporte diminuiu de $6,9 \%$ para $4,6 \%$, algo que ocorreu especificamente na parte continental da Europa em razão da estabilidade econômica lá vivida e do planejamento ferroviário e rodoviário e respectivos investimentos, além do desenvolvimento dos conceitos e práticas de logística (LEITE, 2012).

No entanto, os custos de logística foram responsáveis por 9,8\% do Produto Interno Bruto (PIB) nos Estados Unidos em 2007, caindo para 7,8\% do PIB em 2009, isto como resultado da recessão. Desde então, eles cresceram a 8,5\% do PIB em 2011, mas ainda são mais baixos do que antes da recessão de 2008. Os estudos canadenses mostraram por seu turno que os custos de transporte nas áreas urbanas são 2,6 vezes mais elevados do que os custos nos subúrbios (LEITE, 2012). Os fatos acima mencionados indicaram que a logística da cidade é um dos fatores-chave da sustentabilidade urbana incluindo a questão da sustentabilidade econômica.

A distribuição de mercadorias promove, assim, funções vitais das cidades. Todavia, a concretização eficaz dos fluxos de aprovisionamento é uma condição necessária, mas não suficiente da vida dentro da cidade. De qualquer modo, as dificuldades são grandes em fazer com que os produtos e serviços percorram de maneira fluida o seu ciclo, atendendo a todos com menores custos possíveis e no menor prazo possível (LEITE, 2012).

Para representar em números tais dificuldades e o seu enfrentamento, tem-se, por exemplo, o caso da cidade de Milão na Itália em que 54\% das mercadorias são entregues em $88 \%$ das vans que circulam pela cidade, enquanto as mercadorias restantes, $46 \%$ são transportadas com $12 \%$ dos veículos de carga em circulação (aqueles de maior volume). Isto representou maior fluidez do trânsito, retirando enormes caminhões do trânsito da grande cidade que é Milão, lembrando que São Paulo, metrópole ainda maior, ainda recebe muitos caminhões grandes a fim de distribuir produtos, percorrendo grande parte da malha viária urbana que congestionam o trânsito (FERRI; CHAVES; RIBEIRO, 2015).

Por tais razões, o objetivo da logística da cidade é a harmonização da oferta e da procura, ou seja, a otimização global de fluxos logísticos na cidade (FIGUEIREDO; LAMOUNIER, 1997).

Essas interações fornecem características complexas de logística da cidade e das cadeias logísticas privadas nas cidades implementadas. O que se quer dizer é que uma das características da realidade temática da City Logistics é que a aplicação dos fluxos de mercadorias geralmente não 
depende exatamente da estrutura interna da cidade, embora haja um impacto extremamente interativo entre as duas realidades: o que a empresa planeja e a realidade de cada cidade (FIGUEIREDO; LAMOUNIER, 1997).

Do ponto de vista das teorias a compor a City Logistics, tem-se que as entregas são realizadas de uma forma muito semelhante em todas as cidades, independentemente de suas diferenças. Por outro lado, por meio da análise dos modelos de transporte urbano desenvolvidos por especialistas desde o início deste século, verificou-se que o tamanho e a forma das cidades têm um impacto significativo sobre o desempenho dos fluxos de transporte urbano, tendo por maior impacto a demora em se entregar algo simplesmente porque não há vias diretas entre determinadas ligações ou, ainda que tais vias mesmo existentes não deem conta do fluxo atual (POJANI; STEAD, 2015).

De modo ainda mais amplo, deve-se também avaliar quanto ao estudo em logística urbana que as cidades diferem entre si quanto às características demográficas, geográficas, econômicas, sociais, culturais e históricas. Deste modo, iniciativas e conceitos de logística definidos ou aplicados em determinada cidade não têm o mesmo efeito em outras, carecendo de sucessivos estudos e adaptações (POJANI; STEAD, 2015).

Como se verá no tópico seguinte, estudos e adaptações, seja por parte do poder público, seja por parte de particulares, são necessários para que determinados negócios voltem a prosperar na cidade de Campinas.

\subsection{A Cidade De Campinas}

Os títulos de Califórnia Brasileira ou Vale do Silício Brasileiro passaram a povoar os discursos sobre a estrutura industrial e empresarial da cidade Campinas, isto em meados dos anos de 1980, denotando claramente a grande vocação dessa cidade para a modernidade. A herança cafeicultora e também advinda das usinas de cana-de-açúcar em Campinas concernente aos séculos XVII a XIX foi apontando para um Município com boa velocidade de desenvolvimento econômico, como resultado direto da intensa atividade comercial, agrícola e industrial (FONT, 2016).

Em tais épocas, notadamente a partir de meados do século XIX, as ferrovias percorriam pouco a pouco o interior do país, destinando mais precisamente em relação à produção do café para os portos do país. Assim ocorrera com a Companhia Mogiana, com alguns ramais a percorrer Campinas e região (CANO; BRANDÃO, 2002).

Em salto temporal, os anos de 1940 foram marcados pelo Plano Viário Prestes Maia, com real crescimento urbano e novas obras a ocorrer na cidade entre as décadas de 1960 e 1970 . Foi o caso da construção de longas vias de interligação, como se deu com o viaduto Miguel Vicente Cury e o viaduto São Paulo (CANO; BRANDÃO, 2002).

A cidade permaneceu desenvolvendo-se e caminhando de fato por grande malha viária e corredores urbanos em permanente progressão, alcançando o atual estágio. Prova disto é a existência do importante Terminal Multimodal Ramos de Azevedo que foi inaugurado no ano de 2008 e atende a cidade, os municípios vizinhos e até mesmo o transporte interestadual, abrigando bases de empresas que promovem tal transporte.

Um dos cruzamentos de maior destaque na cidade é o Viaduto São Paulo que passa pela junção Norte-Sul, além da Avenida Princesa D'Oeste que igualmente se conecta a dois túneis fundamentais para tal interligação (CANO; BRANDÃO, 2002).

Duzentas linhas de ônibus urbano e cem linhas de ônibus metropolitanos e intermunicipais perfazem a mobilidade local e regional, além de corredores e avenidas que além de abrigar a 
passagem de muitos veículos, possuem faixas preferenciais para os referidos veículos (CANO; BRANDÃO, 2002).

Apesar desta extensa malha viária e oferta de transporte público, os problemas de mobilidade urbana não são poucos, com mais pessoas procurando deslocar-se e as distâncias entre moradia e trabalho aumentaram-se cada vez mais (FONT, 2016).

O próximo tópico trata dos materiais e métodos aqui adotados, essenciais para compreender os caminhos percorridos pela pesquisa.

\section{MATERIAIS E MÉTODOS}

Trata-se de pesquisa qualitativa, tendo por procedimentos a revisão de literatura que para Okoli e Schabram (2010) é a parte introdutória de qualquer estudo científico ou que relate um caso em específico e o estudo de caso que é indicado em estudos que se pretende entender como determinado fato veio a correr. Um estudo de caso ainda permite com que o pesquisador possa compenetrar-se em um case e manifestar um ponto de vista globalizante e real do mundo em que vive. $\mathrm{O}$ estudo de caso também é usado em muitas situações, para contribuir ao nosso conhecimento dos fenômenos individuais, grupais, organizacionais e sociais (YIN, 2015).

Adiante, o estudo de caso a promover tais pontos de vista desejados, partindo-se da observação indireta dos fatos transcorridos. Os dados apresentados a seguir foram cedidos pela empresa estudada.

\section{RESULTADOS E DISCUSSÃO}

A empresa teve seu nome preservado por questão de sigilo, está localizada no centro da cidade de Campinas, possuindo larga experiência no ramo do comércio de aparelhos auditivos e de acessórios. Com vinte e dois anos de atuação local e regional, tem em seu cadastro cerca de cinco mil clientes registrados, algo que, inclusive, marca sua administração é a anotação de todos os dados cadastrais desde o primeiro cliente.

A perda de receitas e de clientela em números reais fez a empresa rever suas estratégias e seu programa de marketing, iniciando pesquisas para identificar eventuais problemas não relacionados à crise econômica nacional, mas a questões específicas da praça de Campinas.

Em pesquisa realizada sob a coordenação do Departamento de Marketing da companhia, verificou-se que $72 \%$ de seu público morava na região periférica da cidade, algo condizente com a expansão urbana experimentada nas décadas anteriores, afora a elevação dos custos de se residir na região central da cidade. Souza (2015) relatou em seu estudo que a desigualdade social é perceptível também na questão de distribuição da população, com as classes média e alta ocupando principalmente as regiões centrais e de melhor acessibilidade urbana, inclusive para a questão logística e as camadas mais pobres acabam residindo em áreas periféricas mais distantes do centro, dificultando a acessibilidade urbana.

As características das áreas urbanas podem se diferenciar substancialmente, portanto, as medidas de logística urbana tem que ser especificamente concebidos e avaliadas, a fim de implementar a mais eficaz. Logo, conhecer as necessidades da clientela se torna uma oportunidade para os operadores de serviços logísticos conhecerem as necessidades dos clientes e assim atendêlos com presteza, incentivando o processo de melhora constante na operação de logística (GUNASEKARAN, PATEL, TIRTIROGLU, 2001; NUZZOLO; COMI, 2014). 
A empresa relatou que a queda nas vendas acabou por fazer surgir discussões internas importantes sobre como enfrentar os dados obtidos com o detalhamento da pesquisa que apontou que as pessoas ora adiavam sua ida ao centro da cidade por conta de compromissos ou pelo dissabor existente em enfrentar o transporte público quando fosse o caso, ora optavam por comprar de outra empresa os novos equipamentos auditivos, ou mesmo recorrendo a estas organizações quando necessitavam de consertos. E, até mesmo a internet, no caso dos reparos eletrônicos dos aparelhos, passaram a oferecer perda de mercado para a companhia sob análise.

A empresa também informou que na cidade próxima, chamada Americana, existia uma subsidiária de uma multinacional da área de aparelhos auditivos que passou a atender a população periférica de Campinas, precisamente recebendo clientes do noroeste e do oeste da cidade. Notou-se que, em Americana, há grande polo industrial na área da tecelagem, implicando em duas situações relevantes: o elevado ganho per capita da população com problemas auditivos alarmantes registrados no passado por tais trabalhadores das indústrias têxteis, porque anteriormente não eram afeitos às proteções auriculares agora obrigatórias e perante intensa fiscalização do Ministério do Trabalho.

Notou-se que a partir da localização e da estratégia atual da empresa referida, as diversas dificuldades e distâncias (entre seu único ponto de atendimento, a realidade do e-commerce e, ainda, relativa à crise econômica de 2014/2015), quando somadas, de fato passaram a apresentar um quadro prejudicial aos seus negócios, principalmente quando comparadas com o seu concorrente da cidade de Americana.

Deste modo, uma solução precisou ser adotada. Assim, três carros foram adquiridos e, passando pela colocação de adesivos, ficaram à disposição destes seis representantes comerciais já em janeiro de 2015 (até dezembro do mesmo ano), obedecendo a divisão da cidade em 4 grandes áreas a seguirem, sob o sistema de rodízio, a visita desses representantes. Tal solução não seria possível, nos termos em que se deu, sem as mudanças da malha viária promovidas pelo governo municipal da cidade de Campinas.

O centro do município foi interligado com as suas regiões periféricas, conforme a Figura 1. Por meio da Figura 1 pode-se, por exemplo, ver que regiões mesmo distantes uma das outras encontram vias de grande acesso a interligá-las (traços verdes).

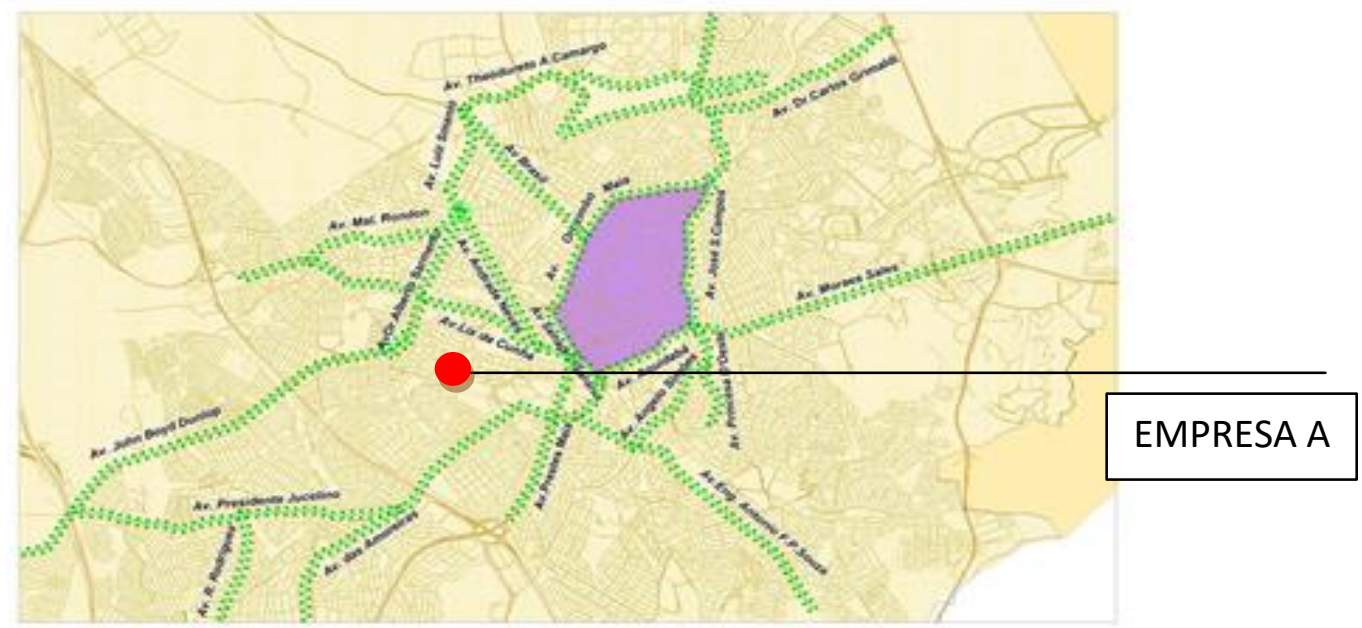

Figura 1 - Principais vias automotivas de Campinas a interligar a região central à região periférica. Fonte: 〈PMC (2014, p.34)〉. Acesso em 09 Set. 2016 
Os ensinamentos sobre logística urbana, principalmente sobre as técnicas de se alcançar mais satisfatoriamente a clientela, como reportaram, mais especificamente no tocante aos idosos, por exemplo, Ferri, Chaves e Ribeiro (2015) encontra lugar no estudo de caso, uma vez a empresa analisada estar há vários quilômetros do centro comercial e do ponto de vendas dos aparelhos auditivos, fazendo com que ela optasse por estratégia diferenciada de atendimento, não mais passivamente aguardando a visita de seus clientes.

A implantação de uma estratégia de aproximação em face da clientela com deficiência auditiva é uma alternativa importante para levar mais dignidade e atendimento para esse público, trazendo vantagem competitiva para a empresa que a realiza (MONTEIRO et al, 2016), como foi o caso.

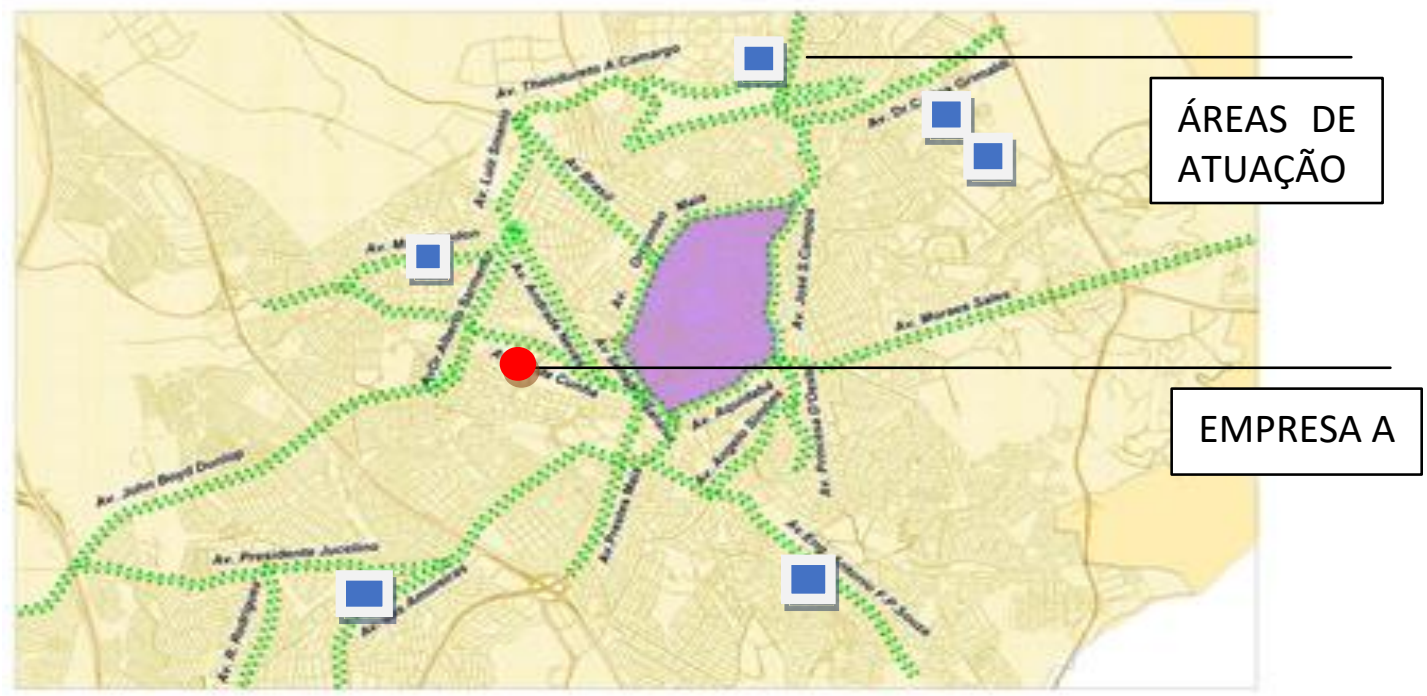

Figura 2 - Áreas de maior atuação dos vendedores de dispositivos auditivos (segundo o estudo de caso). Fonte: PMC (2014, p. 34)>. Acesso em 09 Set. 2016

Com as perdas comerciais e ainda após as pesquisas internas apontarem as causas deste problema, destacou-se a distância entre a residência dos clientes e a loja de vendas dos aparelhos auditivos como a principal causa da perda dos clientes, algo que precisou ser solucionado como sugere as técnicas das vendas porta a porta que é uma técnica defendida por Oliveira et al. (2016) e por Lopes, Cherioni e Dourado (2014).

Estando os clientes perifericamente situados devido à expansão urbana no município, a empresa decidiu ir até o cliente, ou seja, deslocar-se até a sua residência ofertando os produtos e os serviços constantes da venda de aparelhos auditivos e de sua manutenção, o que ocorreu por intermédio da ida dos vendedores a residência dos antigos e novos clientes.

A solução merece destaque em virtude do verdadeiro reposicionamento que a empresa adotou, antigamente mostrando-se passiva quanto à ida de clientes à sua loja fisicamente existente, passando a cumprir estratégia mais ativa de ir ao encontro de sua clientela, exatamente onde está mais confortavelmente situada.

O Gráfico 1 cedido pela empresa mostrará com a linha de corte a oscilação da clientela antes e após a implementação da estratégia em Janeiro de 2015 até Abril de 2017: 


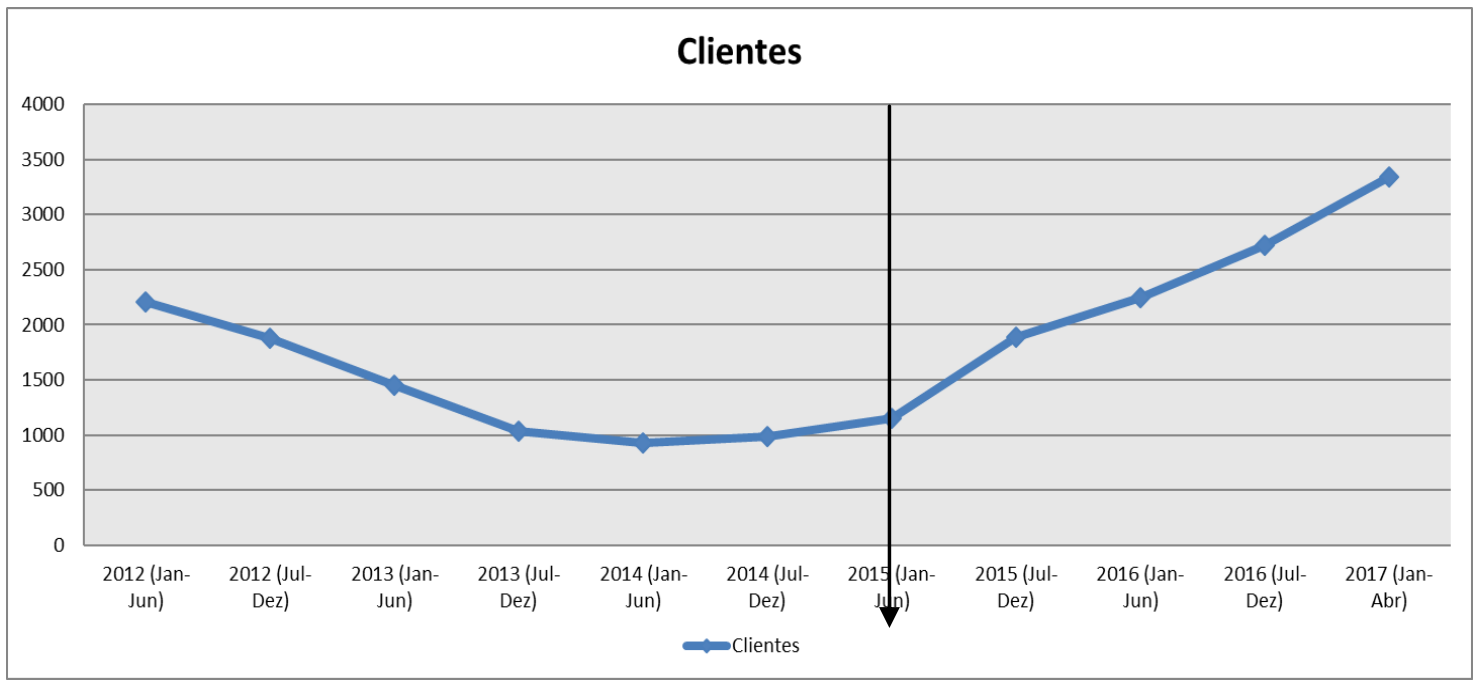

Gráfico 1 - Variações da clientela antes e após a adoção da nova estratégia.

Fonte: Dados da empresa (2017).

Como mostra o Gráfico 1 acima, o aumento da procura de clientes pelo serviço especializado após a implementação da estratégia em 2015 de fato se mostrou existente, nos mesmos moldes dos estudos de Rauta, Fagundes e Sehnem (2014), alcançando os objetivos pretendidos pela nova estratégia: aproveitar reestruturação e construção de grande malha viária a conectar o centro do município com as áreas de sua periferia: a vantagem competitiva facilitada pela malha viária existente, mais do que isto, ligou-se de modo contundente à teoria examinada, realçando a importância do tema e o valor de se buscar soluções concretas na área da logística urbana, como são os esforços atuais das empresas nesta direção (GONZALEZ-FELIU; BASCK; MORGANTI, 2013).

Ressalta-se que, em números, seis vendedores auxiliaram demasiadamente a empresa a observar a mudança do número de clientes (de 1004 clientes em dezembro de 2014, a 3417 em abril de 2017 - destes, 850 no primeiro momento, e, 2503, respectivamente em face dos números acima, são idosos).

Lima et al. (2015) sustentaram em seu artigo, também o alinhamento das questões práticas e teóricas, que foi a coleta e a entrega de produtos no sistema porta a porta, mesmo que em rede considerado (com o planejamento próprio do esquema da distribuição em rede), é algo que pode dar muito certo. Os autores reportaram que no Estado de Rondônia as mercadorias agrícolas encontraram dois modos de escoamento: a distribuição porta a porta e o envio para pequenos redistribuidores possuidores de depósitos estrategicamente situados.

As vias de acesso de determinado local influenciam diretamente na composição e na recomposição das saídas logísticas de distribuição de produtos e serviços (LIMA et al., 2015). Assim como ocorrera em Campinas, as pessoas mais idosas da cidade de Rondônia (com alguma questão de mobilidade relacionada à idade) ou sem veículo próprio, por exemplo, tinham dificuldade de adquirir produtos, carecendo de auxílio dado por vendedores dinâmicos para solucionar o problema.

Controlar a saída da produção em condições de mobilidade urbana ou rural inóspitas, deste modo, assumindo os próprios produtores ou colaboradores que se envolvam de algum modo com o negócio, é uma saída para problemas estruturais ou pontuais que surgem para comerciantes de diversas áreas, mostrando ser exemplo de como resolver situações similares (FONT, 2016). 
Como em Campinas, algumas cidades de Rondônia tiveram, no papel do produtor da agroindústria, como expuseram Lima et al. (2015), soluções que colocaram vendedor e cliente frente a frente, unindo interesses conjunturalmente distantes - algo que as cidades, a partir de seus gestores, precisam melhor se preocupar. Ressaltando a importância de se conhecer as necessidades da clientela, segundo Taniguchi et al. (2001), são os stakeholders que influenciam em diferentes níveis na formulação de projetos de logística urbana, auxiliando na implementação de estratégias adequadas para melhor atendimento às necessidades do consumidor.

City Logistics é campo que contribui com a solução de tais problemas, vez importar-se com locomoção, vias de transporte e acessos diversos, conforme Witkowskia e Kiba-Janiak (2014).

Sem as novas e rápidas vias de acesso que foram criadas pelo governo local de Campinas ao mesmo tempo em que o transporte público em si continuou deficitário, pouco poderia ser planejado e realizado sobre as vendas in loco dadas pelos atendentes da empresa estudada (COSTA; AERE; GUARIENTO, 2014).

\section{CONCLUSÃO}

É possível concluir que as soluções em logística, e mais precisamente, em City Logistics, dependem da vontade de inovar do empreendedor, porque colocando-se realmente em prática ideias antes não pensadas ou que, com o passar do tempo, foram perdendo sua motivação por alguma razão, os resultados podem ser extraordinários.

Isto é dito em função do que se pode retirar da revisão de literatura e do estudo de caso, uma vez que a solução apresentada pela empresa de vendas e a manutenção de aparelhos auditivos se amoldam às teorias e às diversas classificações que visaram criar, melhorar e desenvolver o que se entende por City Logistics. Os resultados apurados pela empresa (o crescimento real de sua clientela, com destaque da população idosa por ela atendida, a se elevar em $294 \%$ após a adoção de sua nova estratégia), bem como sua relação com a literatura examinada fizeram cumprir os objetivos do presente artigo.

Assim, observou-se que os modelos de negócios precisam mudar quando se deparam com problemas diversos, como foi a questão do distanciamento da clientela de determinado ponto central de vendas, isto que ocorreu em Campinas e que obrigou a empresa a adotar novo posicionamento, dirigindo-se até onde o cliente se encontrava. A pergunta de pesquisa foi respondida, pois uma vez que o acesso ao AASI fora facilitado na região periférica da cidade de Campinas, houve um aumento nas buscas pelo serviço especializado.

Interessante notar que as soluções em logística nem sempre são complexas como quando se observa para as questões de acessibilidade, transporte e mobilidade urbana das grandes cidades, precisando o empresário se permitir a enxergar o problema em todos os aspectos e ter a assertividade decisiva em implantar soluções inovadoras no seu segmento de atuação, principalmente pensando-se na questão do idoso.

Por fim, registra-se que o artigo encontrou por limites a avaliação financeira precisa dos custos da mudança estratégica de atendimento ao cliente da empresa que estavam inacessíveis. Todavia, as questões dos custos e de outras quantificações relativas à mudança mostraram a oportunidade para novos trabalhos científicos nesta direção. 


\section{REFERÊNCIAS}

BOWERSOX, D. J.; CLOSS, D. J.; COOPER, M.; ANDERSEN, L. K. B. Supply Chain Logistics Management. 2. ed. Nova York: McGraw-Hill, 2011.

CANO, W.; BRANDÃO, C. A. A Região Metropolitana de Campinas. v. 2. Campinas: Unicamp, 2002.

CARVALHO, M. S. Proposta de Aplicação de um Framework para o Gerenciamento Estratégico de uma Empresa Social. Revista Inovação, Projetos e Tecnologias, v. 4, n. 1, p. 34-49, 2016.

CHRISTOPHER, M. Logística e gerenciamento da cadeia de suprimentos: criando redes que agregam valor. 2. ed. São Paulo: Cengage Learning, 2010.

COSTA, A. M.; AERE, C. L.; GUARIENTO, M. E. Autorrelato de quedas e fatores associados em idosos assistidos na atenção primária no município de Campinas, SP. Revista de Atenção à Saúde (antiga Rev. Bras. Ciên. Saúde), v. 12, n. 42, p. 29-35, 2014.

CRUZ, M. S. et al. Uso de aparelho de amplificação sonora individual por idosos: estudo SABE-saúde, bem-estar e envelhecimento. Audiology-Communication Research, v. 18, n. 2, p. 133-142, 2013.

FERRI, G. L.; CHAVES, G. L. D.; RIBEIRO, G. M. Análise e localização de centros de armazenamento e triagem de resíduos sólidos urbanos para a rede de logística reversa: um estudo de caso no município de São Mateus, ES. ES. Prod., São Paulo, v. 25, n. 1, p. 27-42, 2015

FIALHO, I. M.; BORTOLI, D.; MENDONÇA, G. G.; PAGNOSIM, D. F.; SCHOLZE, A. S. Percepção de idosos sobre o uso de AASI concedido pelo Sistema Único de Saúde. Revista CEFAC, v. 11, n. 2, p. 338-344, 2009.

FONT, T. G. Terminais de transporte público e o surgimento de novas centralidades de Campinas. Dissertação (Mestrado em Urbanismo). Centro de Ciências Exatas, Ambientais e de Tecnologias. Pontifícia Universidade Católica de Campinas, Campinas, 2016.

FIGUEIREDO, R.; LAMOUNIER, B. As Cidades Que Dão Certo. 5. ed. Brasília: Mh Comunicação, 1997.

GATEHOUSE, S.; NAYLOR, G.; ELBERLING, C. Linear and non-linear hearing aid fittings-2. Patterns of candidature. Int Audiol, v. 45, n. 3, p. 153-171, 2006.

GATES, G. A.; MURPHY, M.; REES, T. S.; FRAHER, A. Screening for handicapping hearing loss in the elderly. Journal of Family Practice, v. 52, n. 1, p. 56-62, 2003.

GONZALEZ-FELIU; J. BASCK, P.; MORGANTI, E. Urban logistics solutions and financing mechanisms: a scenario assessment analysis. European Transport $\backslash$ Transporti Europei, v. 11, n. 54, p.1-16, 2013.

GUNASEKARAN, A.; PATEL, C.; TIRTIROGLU, E. Performance measures and metrics in a supply chain environment. International Journal of Operations \& Production Management, v. 21, n. 1/2, p. 71-87, 2001.

IBGE. Instituto Brasileiro de Geografia e Estatística. Rio de Janeiro: IBGE, 2016.

JARDIM, D. S.; MACIEL, F. J.; LEMOS, S. M. A. Perfil epidemiológico de uma população com deficiência auditiva. Revista CEFAC, v. 18 n. 3, p. 746-757, 2016.

KOTLER, P. Marketing para o século XXI: como criar, conquistar e dominar mercados. São Paulo: Futura, 1999.

LEITE, C. Cidades Sustentáveis, Cidades Inteligentes. Porto Alegre: Bookman, 2012.

LEONG, C. M. L et al. The Emergence of Self-Organizing E-Commerce Ecosystems in Remote Villages of China: A Tale of Digital Empowerment for Rural Development. Mis Quarterly, v. 40, n. 2, p. 475-484, 2016.

LIMA, C. C.; MAGRO, E. F. D.; ANDRADE, L. M. N.; QUINTINO, S. M. Empreender na Gestão Agropecuária da Amazônia: o Caso das Agroindústrias Familiares em Rondônia. Revista Metropolitana de Sustentabilidade, v. 5, n. 2, p. 49-74, 2015.

LOPES, A. M. P.; CHERIONI, R. C. P. F.; DOURADO, C. A. Marketing para a Classe C: Um novo perfil para consumidoras de vestuários em Franca. Fórum de Administração, v. 5, n. 2, p. 27-38, 2014.

LUPSAKKO, T. A.; KAUTIAINEN, H. J.; SULKAVA, R. The non use of hearing aids in people aged 75 years and over in the city of Kuopio in Finland. Eur Arch Otorhinolaryngol, v. 262, n. 3, p. 165-169, 2005.

MARTINS, V. Cidade-laboratório: Campinas e a febre amarela na aurora republicana. História, Ciências, Saúde, v. 22, n. 2, abr./jun. p. 507-524, 2015. 
MIYATA, H.; SUZUKI, J. C. Venda Direta na Região Metropolitana de São Paulo: precarização do trabalho e reprodução ampliada do capital. Meridiano - Revista de Geografia, v. 2, n. 2, p. 159-180, 2013.

MONTEIRO, D. C. et al. Solução para Queda de Vendas em uma Empresa Paulistana de Pequeno Porte no Ramo de Aparelhos Auditivos. Revista Inovação, Projetos e Tecnologias, v. 4, n. 2, p. 252-264, 2016.

NOVAES, M. Suprimentos em Logística. São Paulo: Ed. Independência, 2007.

NUZZOLO, A.; COMI, A. Direct effects of city logistics measures and urban freight demand models. In: Jesus Gonzalez-Feliu, Frederic Semet, Jean-Louis Routhier (Eds.) Sustainable urban logistics: concepts, methods and information systems, EcoProduction. Berlin Heidelberg: Springer-Verlag, 2014, p. 211-226.

OKOLI, C.; SCHABRAM, K. A guide to conducting a systematic literature review of information systems research. Sprouts Work. Pap. Inf. Syst, v. 10, n. 26, p. 1-51, 2010.

OLIVEIRA, L. K; OLIVEIRA, R. S; HENRIQUES, R. S; DENAIS, M. Análise dos benéficos de um espaço logístico na distribuição urbana de mercadorias. Revista Produção Online, v. 16, n. 3, p. 988-1006, 2016.

PANHAN, A. M.; MENDES, L. S.; BREDA, G. D. Construindo Cidades Inteligentes. Santos: Editora APPRIS, 2016.

PMC. Prefeitura Municipal de Campinas. Anuário Estatístico de Campinas. Campinas: PMC, 2014.

POJANI, D.; STEAD, D. Sustainable urban transport in the developing world: beyond megacities. Sustainability, v. 7, n. 6, p. 7784-7805, 2015.

RAUTA, J.; FAGUNDES, J. R.; SEHNEM, S. Gestão Ambiental a Partir da Produção Biodinâmica: Uma Alternativa a Sustentabilidade em Uma Vinícola Catarinense. Revista de Gestão Ambiental e Sustentabilidade, v. 3, n. 3, p. 135-154, 2014.

RAZZOLINI, E. F. Logística - evolução na administração - desempenho e flexibilidade. Curitiba: Juruá, 2013.

SOUZA, G. A. Produção do espaço e mobilidade urbana: na contramão da sustentabilidade. Revista Produção e Desenvolvimento, v. 1, n. 3, p. 42-51, 2015.

TADEU, H. F. B. Logística Aeroportuária Análises Setoriais e o Modelo de Cidades Aerop. Guarulhos: Cengage Learning, 2011.

TANIGUCHI, E.; THOMPSON, R. G.; YAMADA, T.; VAN DUIN, J. H. R. City Logistics: Network Modeling and Intelligent Transport Systems. London: Ed. Pergamon. 2001.

WITKOWSKIA, J.; KIBA-JANIAK, M. The role of local Governments in the development of city logistics. ProcediaSocial and Behavioral Sciences, v. 125, p. 373-385, 2014.

YIN, R. K. Estudo de caso: planejamento e métodos. 5. ed. Porto Alegre: Bookman, 2015. 